\title{
High-throughput analysis of multiple stress pathways using GFP reporters in C. elegans
}

\author{
D. de Pomerai ${ }^{1}$, C. Anbalagan ${ }^{1}$, I. Lafayette ${ }^{1}$, D. Rajagopalan ${ }^{1}$, \\ M. Loose ${ }^{1}$, M. Haque ${ }^{2}$ \& J. King ${ }^{2}$ \\ ${ }^{1}$ School of Biology, University of Nottingham, UK \\ ${ }^{2}$ School of Mathematical Sciences, University of Nottingham, UK
}

\begin{abstract}
Stress-responsive genes belonging to multiple defensive pathways in the nematode $C$. elegans are cross-regulated by kinase signalling (AKT-1/-2, p38 MAPK) and transcription factors (DAF-16, SKN-1). This cross-talk between stress pathways implies that they are best regarded as a stress-response network (SRN), whose behaviour as a whole should be amenable to mathematical modelling. We have used GFP reporter strains to provide a rapid readout of expression levels for 24 genes, representing principal outputs and transcription factors in the heat-shock, metal-binding, oxidative stress, phase I \& phase II detoxification, and genotoxic stress pathways. Acute toxicity data (up to $\sim 24 \mathrm{~h}$ ) has been generated for selected metal (presented here) and pesticide toxicants across a wide range of doses, and common response patterns identified. Mathematical modelling of these response data, informed by an understanding of the underlying genetic circuitry, should allow our model to predict the likely toxicity of pollutant mixtures. Future work will test the accuracy of such predictions, leading to an iterative process of model refinement.
\end{abstract}

Keywords: metal toxicity, caenorhabditis elegans, mathematical modelling, mixture toxicity, high-throughput GFP reporter assays, stress-response network.

\section{Introduction}

Both chemical and physical (e.g. heat) stressors evoke defensive responses in living organisms - including DNA repair to counteract genotoxic DNA damage, heat-shock protein (hsp) expression to counter proteotoxic (e.g. thermal) damage to proteins, metal-binding proteins to sequester heavy metals, phase I and phase 
II detoxification enzymes to metabolise complex organic compounds, and oxidative stress enzymes to deal with reactive oxygen species (ROS). Several of these pathways can be activated by a single agent: cadmium $(\mathrm{Cd})$ is genotoxic, binds to reduced glutathione thus increasing ROS levels, and is a potent inducer of hsp expression. Paradoxically, cadmium can also induce the expression of multiple cytochrome P450 (cyp) genes, as revealed by gene-array studies in the nematode $C$. elegans [1]; we and others have demonstrated that for the cyp-34A9 gene at least, $\mathrm{Cd}$ regulation is probably mediated by the DAF-16 transcription factor regulating longevity [2, 3]. Indeed, DAF-16 acts as a positive regulator for many other stress-response genes, including sod-3 (mitochondrial superoxide dismutase) and $m t l-1$ (metal-binding metallothionein) as well as $h s p-16.1$ and hsp-16.2 (encoding small hsp's) [3]. Thus functionally distinct stress-response pathways are clearly cross-regulated by core transcription factors in C. elegans.

C. elegans is a useful genetic model in which to examine this stress-response network (SRN) as a whole, thanks to its ease of culture, short life cycle, excellent genetics, complete genome sequence and numerous post-genomic tools including feeding RNAi screens to explore gene functions. In the context of environmental toxicology, it also has certain disadvantages - being relatively resistant to most stressors thanks to an impressive armoury of defensive pathways, including over 80 cyp phase I and 40 gst (glutathione S-transferase) phase II genes. One obvious way to explore genome-wide transcriptional responses to stressors is to use gene arrays, but cost considerations preclude this for routine screening of multiple toxicants over a range of doses, let alone applying this methodology to mixtures. We have adopted an alternative approach employing transcriptional GFP fusion genes (with an EGFP coding sequence driven by $\sim 3 \mathrm{~kb}$ of upstream promoter). Integrated transgenic strains carrying multiple copies of such GFP reporter genes have been provided for us by the Baillie Genome GFP Project or obtained from CGC and other sources. GFP fluorescence levels provide a high-throughput quantitative measure of transgene expression in real time, allowing several time points as well as multiple stress genes, toxicants and test doses to be compared. We aim to develop a predictive mathematical model describing SRN behaviour.

This paper reports GFP expression patterns for 24 test genes in response to 7 metals $\left(\mathrm{Zn}^{2+}, \mathrm{Cd}^{2+}, \mathrm{Hg}^{2+}, \mathrm{Cu}^{2+}, \mathrm{Fe}^{3+}, \mathrm{Cr}^{6+}, \mathrm{As}^{3+}\right)$, as well as preliminary data on metal mixture toxicity. The genes chosen include many of those involved in combating oxidative stress ( $\operatorname{sod}-1$, sod-3, sod-4, ctl-2; \& 2 uncurated glutathione peroxidise genes - T09A12.2 designated GPA and C11E4.1 designated GPB), 2 metallothionein genes ( $m t l-1$ and $m t l-2)$ [4] and several heat-shock genes ( $h s p-3$, $h s p-3$, hsp-60, hsp-16.1, hsp-16.2; \& the uncurated C12C8.1 gene encoding a major cytosolic HSP70 designated cHSP70). Genes encoding key transcription factors involved in regulating these pathways are also included:- skn-1 (affecting oxidative stress genes) [5], $h s f-1$ (regulating heat-inducible $h s p$ genes), daf-16 [3, 6], and elt-2 (controlling adult intestinal genes including both $\mathrm{mtl}$ genes) [7], as well as the p53 orthologue cep-1 involved in responding to genotoxic stress [8]. Among the many phase 1 and phase II genes, only a few candidates already known to be stress-inducible have been included:- these are cyp-29A2, cyp-34A9 and cyp-35A2 [9], as well as gst-1 and gst-4 [10,11]. 


\section{Materials and methods}

\subsection{Materials}

PC161 (hsp-16.1::GFP:lacZ) was developed in-house [12]; grateful thanks are extended to Cynthia Kenyon for CF1553 (sod-3::GFP), Chris Link for CL2050 (hsp-16.2::GFP), Joel Rothman for JR2474 (cep-1::GFP), Ralph Menzel for a strain with pPD97 87-35A2prIII-GFP (cyp-35A2::GFP) and the Caenorhabditis Genetics Center (funded by the NIH National Center for Research Resources) for TJ356 (daf-16::GFP). Other strains were supplied as integrated promoter::GFP fusions by the Baillie Genome GFP Project (Simon Fraser University, Burnaby, Vancouver, Canada), each containing about $3 \mathrm{~kb}$ of upstream promoter sequence (apart from $\mathrm{BC} 20306$ which contains only the $250 \mathrm{bp}$ of promoter separating the cyp-34A9 gene from its upstream neighbour cyp-34A10) [2, 13]. These are:BC17553 (T09A12.2 glutathione peroxidase designated GPA::GFP), BC20303 (hsp-6::GFP), BC20305 (C11E4.1 glutathione peroxidise designated GPB::GFP), BC20306 (cyp-34A9::GFP), BC20308 ( $h s p-3:: G F P)$, BC20309 (mtl-1::GFP), BC20314 (elt-2::GFP), BC20316 (gst-1::GFP), BC20329 (skn-1::GFP), BC20330 (gst-4::GFP), BC20333 (sod-4::GFP), BC20334 (cyp-29A2::GFP), BC20336 (ctl-2::GFP), BC20337 ( $h s f-1:: \mathrm{GFP}$ ), BC20342 ( $m t l-2:: \mathrm{GFP}$ ), BC20343 (hsp60::GFP), BC20349 (C12C8.1 hsp-70 designated cHSP70::GFP) and BC20350 (sod-1::GFP). All patterns of induced and uninduced GFP expression have been verified against expression data (where known) for the corresponding gene on Wormbase. All chemicals were from Sigma Ltd and plasticware from Nunc Ltd.

\subsection{Methods}

All GFP reporter strains were grown at $15^{\circ} \mathrm{C}$ on NGM agar plates with a lawn of P90C E. coli as food [14]; worms were harvested after 3-4 days of culture, and equal aliquots of $\sim 500$ worms (all stages) were exposed to increasing sublethal doses of metal ions diluted in $\mathrm{K}$ medium $(53 \mathrm{mM} \mathrm{NaCl}, 32 \mathrm{mM} \mathrm{KCl})$ [15]. The dose ranges tested were:- $0.32-200 \mathrm{ppm} \mathrm{Zn}^{2+}, 0.022-22 \mathrm{ppm} \mathrm{Cd}^{2+}, 0.016-10 \mathrm{ppm}$ $\mathrm{Hg}^{2+}, 0.06-15 \mathrm{ppm} \mathrm{Cu}^{2+}, 0.01-100 \mathrm{ppm} \mathrm{Fe}^{3+}, 0.064-40 \mathrm{ppm} \mathrm{Cr}^{6+}$ (as $\mathrm{Cr}_{2} \mathrm{O}_{7}{ }^{2-}$ ) and 0.01-100 $\mathrm{ppm} \mathrm{As}^{3+}$ (as $\mathrm{AsO}_{2}{ }^{-}$) [15]; in all cases, a set of zero controls (no metal) was also included. After 4-6 (early), 8-12 (intermediate) or 24-30 (late) hours of exposure, all worms were transferred into black non-fluorescent 96-well plates and the levels of GFP fluorescence measured in a Perkin-Elmer Victor 1420 plate fluorometer. Full details of this methodology will be published separately. Four independent assays were conducted for each test condition, and the means \pm SEMs compared using one-way ANOVA and Dunnett's multiple comparisons test. Typical GFP data are shown in Figure 1 for three genes responding to $\mathrm{Hg}^{2+}$. 
A. $m t l-1$ at $4 \mathrm{hrs}$

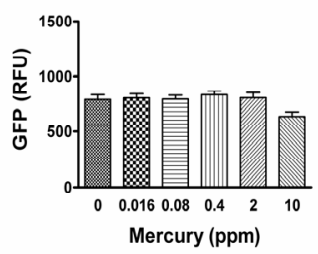

D. $m t l-2$ at $4 \mathrm{hrs}$

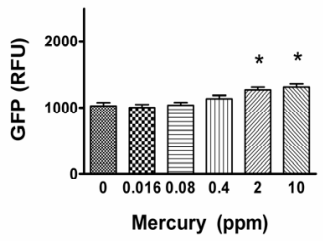

G. elt-2 at $4 \mathrm{hrs}$

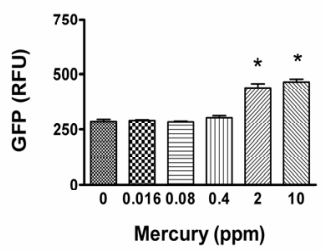

B. $m t l-1$ at $8 \mathrm{hrs}$

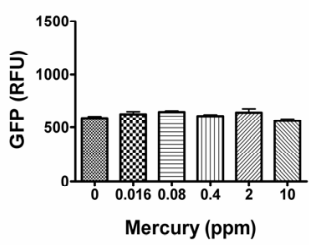

E. $m t l-2$ at $8 \mathrm{hrs}$

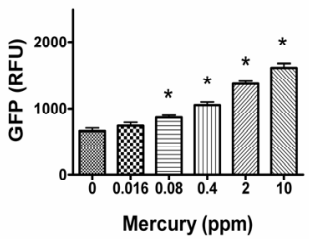

H. elt-2 at $8 \mathrm{hrs}$

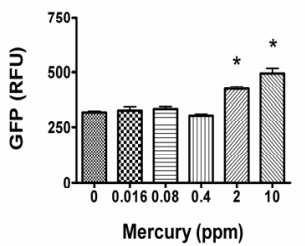

C. $m$ tl-1 at $24 \mathrm{hrs}$

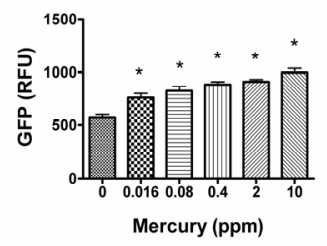

F. $m t /-2$ at $24 \mathrm{hrs}$

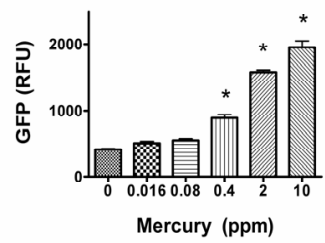

I. elt-2 at $24 \mathrm{hrs}$

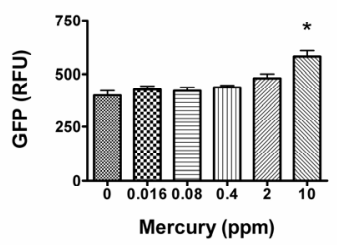

Figure 1: $\quad$ Expression of metallothionein-related GFP reporters in response to Hg. Reporter GFP strains transgenic for $m t l-1$ (A-C), $m t l-2$ (D-F) or elt-2 (G-I) were exposed to the indicated concentrations of $\mathrm{HgCl}_{2}$ (5-fold dilutions from $10 \mathrm{ppm}$ down to $16 \mathrm{ppb}$, plus zero controls) for $4 \mathrm{hr}(\mathrm{A}, \mathrm{D}, \mathrm{G}), 8 \mathrm{hr}(\mathrm{B}, \mathrm{E}, \mathrm{H})$ or $24 \mathrm{hr}(\mathrm{C}, \mathrm{F}, \mathrm{I})$, and GFP expression was measured (in relative fluorescence units, RFU) as described in methods. After applying one-way ANOVA and Dunnett's post hoc multiple comparisons test to the data within each figure, expression levels that differ significantly from zero controls at the same time point are indicated by asterisks $(\mathrm{p}<0.05$; $\mathrm{n}=4$ in all cases).

\section{Results}

By its very nature, a high-throughput study of multiple genes and toxicants generates large volumes of data. The first stage in data compilation is exemplified by Figure 1, which shows the responses to $\mathrm{Hg}^{2+}$ of 3 functionally related genes (the $2 C$. elegans metallothionein genes, $m t l-1$ and $m t l-2$, plus their candidate transcriptional activator elt-2), comparing a range of 5-fold doses (0 plus $16 \mathrm{ppb}$ up to $10 \mathrm{ppm}$ ) at 3 different time points (4, 8 and 24 hours). GFP expression levels that differ significantly from zero-Hg controls are indicated by asterisks ( $\mathrm{p}<0.05$ using Dunnett's test). Broadly speaking, mtl-1 shows less 
clear-cut induction than $m t l-2$, in agreement with previous findings [4]; the $m t l-1$ gene is expressed constitutively in the posterior pharynx, and is inducible in the intestine of larvae, but less so in adults [4]. Since assays were conducted on mixed stage cultures, it is possible that the stronger induction of this gene seen at $24 \mathrm{hrs}$ (significant at all test doses) reflects $m t l-1$ induction in a new generation of young larvae. Notably, $m t l-2$ expression is already induced at $4 \mathrm{hrs}$ at the highest test doses, and shows clear dose-dependent induction at the later time points. By contrast, elt-2 expression is only activated at the two highest concentrations of $\mathrm{Hg}^{2+}$, and even this response fades out somewhat by $24 \mathrm{hrs}$.

It would clearly be impractical to extend this presentation to 6 other metals and to all 24 test genes included in this study. A first-level simplification is shown in Table 1, which summarises the responses to $\mathrm{Hg}^{2+}$ of a larger group of 7 heat-shock related genes ( $h s p-3, h s p-6, h s p-60, h s p-16.1, h s p-16.2$, the uncurated C12C8.1 gene encoding an inducible cHSP70, and their key transcription factor gene, $h s f-1$ ). For simplicity, the early response data (at $4 \mathrm{hrs)} \mathrm{have} \mathrm{been} \mathrm{omitted,}$ as only $h s p-16.1$ showed any response at this time point. Rather than presenting measured GFP data in both zero controls and at each test dose, Table 1 presents simple ratios (mean GFP level at test dose divided by mean GFP level in zero control at that time point) indicating relative induction or repression of transgene expression. In accordance with the common practice for gene array data, Table 1 highlights significant $(\mathrm{p}<0.05)$ expression changes of $>50 \%$ (up or down), and also underlines all changes $>2$-fold. A greater diversity of expression responses is apparent here, with some genes (e.g. $h s p$-16.1) showing greater sensitivity to $\mathrm{Hg}^{2+}$ than others, while $h s p-60$ is virtually unaffected. As for Figure 1, the core transcription factor (here $h s f-1$ ) is much less sensitive than many of its target genes; however, it too is activated at the highest test dose at $8 \mathrm{hrs}$, suggesting that additional transcription factor expression can be deployed in an emergency.

A final level of simplification is shown in Table 2 for the complete set of 7 metals and 24 GFP transgenes. The entries in each cell record only the maximal effect seen (at any dose or time point) for that toxicant on that test gene. Broadly speaking, + or - symbols indicate a statistically significant $(\mathrm{p}<0.05)$ rounded change of between 1.5- and 2-fold (up or down), while ++ indicates a 2- to 3-fold and $+++\mathrm{a}>3$-fold up-regulation of expression (no cases of $>2$-fold downregulation were seen in this data set); the maximal induction seen was about 4.5fold. Some general trends apparent within this large data set are discussed below. Whilst much important detail has been lost, a more complete overview emerges.

One of the major aims of this collaborative study is to develop a predictive mathematical model describing the behaviour of the SRN as a whole. As a start, the mathematicians involved ( $\mathrm{MH}$ and $\mathrm{JK}$ ) have generated initial models of two regulatory sub-networks - one linking the ELT-2 transcription factor to the $2 \mathrm{mtl}$ genes, and the other linking HSF-1 to inducible heat-shock genes; only the former is considered here. A decade ago, Moilanen et al [16] suggested that both $m t l$ genes are positively regulated by ELT-2, which has recently been implicated as the major transcription factor maintaining intestine-specific patterns of gene expression in the adult [7]. We have used RNAi to show that ELT-2 is required 
.

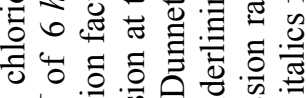

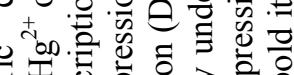

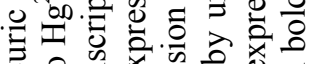

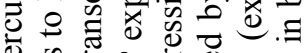

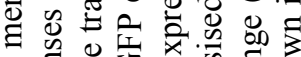
के ญ्ञ

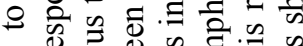
仓

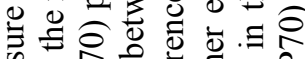
क

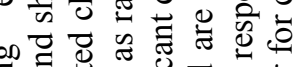
.

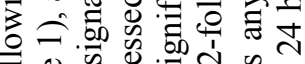
क्ण .00

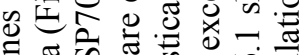
ฐ

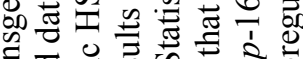
预

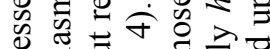
षิ

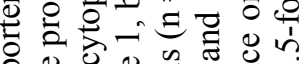

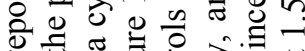
ॠ

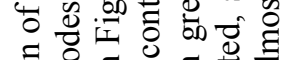

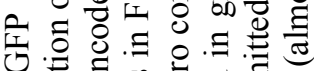

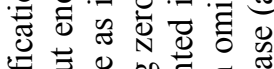
రृ

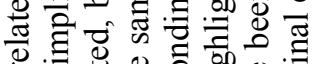


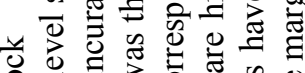

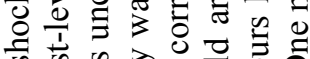

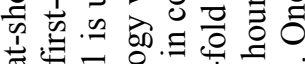
芯匹

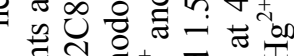
+ ปัँ

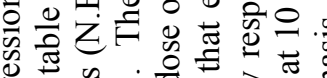

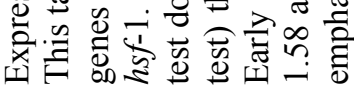

\begin{tabular}{|c|c|c|c|c|c|c|c|c|}
\hline 串 & 을 & ¿্t) & کุ & $\stackrel{?}{\stackrel{n}{q}}$ & $\stackrel{N}{I}$ & 于. & $\stackrel{\text { ఫे }}{-}$ & ָે \\
\hline 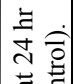 & $\sim$ 言 & $\underset{-}{\tilde{\sigma}}$ & $\stackrel{n}{q}$ & $\stackrel{0}{\stackrel{0}{+}}$ & 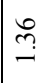 & $\stackrel{8}{\circ}$ & $\stackrel{n}{n}$ & $\stackrel{2}{=}$ \\
\hline $\begin{array}{ll} & 0 \\
0 & 0 \\
0 & 0 \\
0 & 0 \\
0 & 0 \\
0\end{array}$ & $\stackrel{+}{\circ}$ : & $\stackrel{m}{\rightarrow}$ & $\stackrel{ \pm}{-}$ & 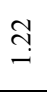 & $\Xi$ & @. & $\hat{ָ}$ & $\stackrel{\Xi}{ت}$ \\
\hline $\begin{array}{ll} & 0 \\
0 \\
0 \\
0 \\
0 \\
0\end{array}$ & $\stackrel{\infty}{\stackrel{0}{0}}:$ & $\stackrel{\Xi}{\stackrel{\sim}{\sim}}$ & กิ & $\stackrel{\text { ঙิ }}{\longrightarrow}$ & $\stackrel{n}{=}$ & å & 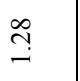 & $\Xi$ \\
\hline \begin{tabular}{ll}
$\vec{x}$ & 0 \\
0 & 0 \\
2 & 0 \\
\multicolumn{1}{c}{} & 0
\end{tabular} & 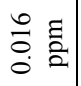 & 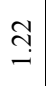 & 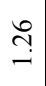 & $\stackrel{\simeq}{\leftrightarrows}$ & $\stackrel{8}{\circ}$ & $\stackrel{\Xi}{\text { d }}$ & $\stackrel{0}{=}$ & $\stackrel{0}{=}$ \\
\hline & ○ 苛 & $\underset{-}{\stackrel{-}{-}}$ & $\stackrel{8}{-}$ & $\stackrel{8}{-}$ & $\stackrel{8}{-}$ & $\stackrel{8}{-}$ & $\stackrel{8}{\circ}$ & $\stackrel{8}{-}$ \\
\hline & 을 & 이 & $\begin{array}{l}\infty \\
\infty \\
-\end{array}$ & $\tilde{n}$ & 함 & $\stackrel{\text { I }}{-}$ & $\stackrel{\infty}{\stackrel{\infty}{\sim}}$ & $\stackrel{\text { J }}{-}$ \\
\hline $\begin{array}{ll}0 & 0 \\
0 & 0 \\
0 & 0 \\
0 & 0 \\
0\end{array}$ & $\sim$ ڤี & $\underset{\sigma}{\widetilde{\sigma}}$ & $\underset{\sim}{\stackrel{J}{*}}$ & $\stackrel{ \pm}{I}$ & $\stackrel{\mathbb{N}}{\mathrm{I}}$ & $\stackrel{\varrho}{=}$ & $\stackrel{n}{m}$ & $\stackrel{ \pm}{\stackrel{4}{2}}$ \\
\hline 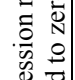 & $\stackrel{t}{\circ}$ : & $\stackrel{m}{\rightarrow}$ & $\stackrel{n}{-}$ & 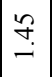 & F & $\stackrel{+}{0}$ & 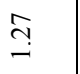 & 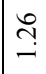 \\
\hline 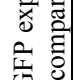 & 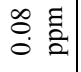 & $\stackrel{\infty}{\underset{N}{-}}$ & $\vec{m}$ & $\stackrel{\ominus}{-}$ & $\stackrel{\infty}{\mathfrak{n}}$ & ڤ̆ & $\stackrel{2}{\rightleftarrows}$ & $\stackrel{\infty}{\stackrel{c}{\sim}}$ \\
\hline 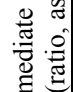 & 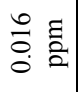 & ָે & $\stackrel{\sim}{\stackrel{n}{g}}$ & 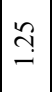 & $\stackrel{\text { I }}{\longrightarrow}$ & $\stackrel{ }{=}$ & $\stackrel{9}{\leftrightarrows}$ & $\stackrel{\overbrace{}}{\overbrace{}}$ \\
\hline & ○ 荾 & $\stackrel{8}{-}$ & $\stackrel{8}{-}$ & $\stackrel{8}{-}$ & $\stackrel{8}{-}$ & $\stackrel{8}{.}$ & $\stackrel{8}{\circ}$ & $\stackrel{8}{\circ}$ \\
\hline & $\begin{array}{ll}0 & 0 \\
0 & 0 \\
0 & 0 \\
0 & 0 \\
& 0 \\
\end{array}$ & 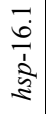 & \begin{tabular}{l}
\multirow{2}{0}{} \\
$\frac{1}{1}$ \\
3 \\
3
\end{tabular} & $\begin{array}{l}0 \\
0 \\
2 \\
2 \\
2\end{array}$ & $\begin{array}{l}0 \\
1 \\
\vdots \\
3\end{array}$ & $\begin{array}{l}8 \\
0 \\
1 \\
\vdots \\
3 \\
3\end{array}$ & 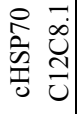 & $\frac{1}{3}$ \\
\hline
\end{tabular}

$\frac{0}{0}$ 
Table 2: $\quad$ Summary of responses for 7 metals in all 24 GFP transgenic strains. These table entries summarise the maximum responses seen across the sublethal doses tested, without distinguishing whether these are dose-dependent or seen only at the maximum dose, nor whether they were observed early (rarely), or at intermediate or late time points. In all cases, no entry in a cell signifies a test:control ratio of 0.67 to 1.45 ( $<1.5$-fold change) $;+$ indicates a ratio of 1.45 to 1.94 (1.5-2 fold up); ++ indicates a ratio of 1.95 to 2.94 (2-3 fold up); +++ indicates a ratio $>2.95$ (3-fold up); and - indicates a ratio of 0.66 to 0.5 (1.5-2 fold down). All such expression changes are statistically significant $(\mathrm{p}<0.05 ; \mathrm{n}=4)$. Ratios have in all cases been rounded to the first decimal place.

\begin{tabular}{|c|c|c|c|c|c|c|c|}
\hline Metal $\rightarrow$ & \multirow[t]{2}{*}{$\mathrm{Zn}^{2+}$} & \multirow[t]{2}{*}{$\mathrm{Cd}^{2+}$} & \multirow[t]{2}{*}{$\mathrm{Hg}^{2+}$} & \multirow[t]{2}{*}{$\mathrm{Cu}^{2+}$} & \multirow[t]{2}{*}{$\mathrm{Fe}^{3+}$} & \multirow[t]{2}{*}{$\mathrm{Cr}^{6+}$} & \multirow[t]{2}{*}{$\mathrm{As}^{3+}$} \\
\hline Gene $\downarrow$ & & & & & & & \\
\hline$m t l-1$ & ++ & + & + & ++ & & & + \\
\hline$m t l-2$ & ++ & +++ & +++ & + & ++ & & + \\
\hline elt -2 & ++ & & + & ++ & & ++ & \\
\hline$h s p-16.1$ & ++ & +++ & ++ & + & +++ & + & ++ \\
\hline$h s p-16.2$ & ++ & ++ & + & +++ & +++ & + & +++ \\
\hline$h s p-3$ & + & +++ & + & +++ & + & & \\
\hline hsp-6 & + & ++ & ++ & ++ & + & + & ++ \\
\hline$h s p-60$ & ++ & ++ & + & +++ & & ++ & ++ \\
\hline $\begin{array}{l}\text { cHSP70 } \\
\mathrm{C} 12 \mathrm{C} 8.1\end{array}$ & + & + & + & ++ & & ++ & + \\
\hline$h s f-1$ & + & + & + & + & - & & \\
\hline sod-1 & + & & + & + & & ++ & \\
\hline sod-3 & - & & + & ++ & & & \\
\hline sod-4 & ++ & ++ & ++ & & +++ & + & + \\
\hline$c t l-2$ & + & & + & & - & & \\
\hline $\begin{array}{c}\text { GPA } \\
\text { T09A12.2 }\end{array}$ & ++ & & + & ++ & ++ & & \\
\hline $\begin{array}{c}\text { GPB } \\
\text { C11E4.1 }\end{array}$ & ++ & + & + & ++ & ++ & & ++ \\
\hline$s k n-1$ & + & & + & & & & \\
\hline gst-1 & +++ & + & + & ++ & - & + & ++ \\
\hline gst-4 & + & ++ & + & ++ & & ++ & + \\
\hline cyp-29A2 & ++ & ++ & + & ++ & & & + \\
\hline cyp-34A9 & ++ & ++ & + & + & + & & ++ \\
\hline cyp-35A2 & +++ & + & ++ & ++ & + & + & ++ \\
\hline cep-1 & ++ & & + & + & & + & + \\
\hline$d a f-16$ & + & & & & ++ & & + \\
\hline
\end{tabular}


for $\mathrm{Cd}$ or $\mathrm{Hg}$ induction of $m t l-2:: \mathrm{GFP}$ expression, though the effect on $m t l$ $1:: G F P$ is less clear-cut (CA and DdeP, unpublished data). Because elt-2 and most intestine-specific genes are expressed constitutively, the low levels of intestinal $m t l$ gene expression in the absence of metal induction additionally require an unknown metal-sensitive repressor [16] - still elusive despite a decade of further research. However, since ectopic expression of ELT-2 activates $m t l$ expression outside the intestine in the absence of metals, this key feature of the model seem to be vindicated. This genetic circuit forms the basis of our mathematical model, which will be published separately $(\mathrm{MH}$, DdeP and JK, in preparation). The broad quantitative patterns of $m t l$ gene induction (Figure 1; top 2 lines of Table 2) are consistent with metal binding (both to MTL proteins and to the unknown repressor) being very much more rapid than the inducibility of $m t l$ gene expression promoted by ELT-2. Assuming that the system does not reach equilibrium within the time course tested (up to 24 hours), then our model predicts that chemically similar divalent metal ions, such as $\mathrm{Zn}, \mathrm{Cd}$ and $\mathrm{Hg}$ (all of which bind to MTLs) should show additive effects on $m t l-2::$ GFP transgene expression, as confirmed for sub-maximal doses of $\mathrm{Cd}^{2+}$ and $\mathrm{Hg}^{2+}$ in Figure 2A. However, $m t l-2$ is also inducible by trivalent $\mathrm{Fe}^{3+}$ at high concentrations $(\sim 100$ $\mathrm{ppm}$ ), although lower doses have little effect. Surprisingly, mixtures of $\mathrm{Fe}^{3+}$ with any of the divalent group IIB metals show interference, i.e. reduced $m t l-2:: \mathrm{GFP}$ expression compared with the divalent ion on its own (shown for $\mathrm{Fe}^{3+}$ and $\mathrm{Hg}^{2+}$ in Figure 2B). This can be accommodated by the mathematical model if $\mathrm{Fe}^{3+}$ interferes with divalent-ion binding to MTLs and/or to the unknown repressor.
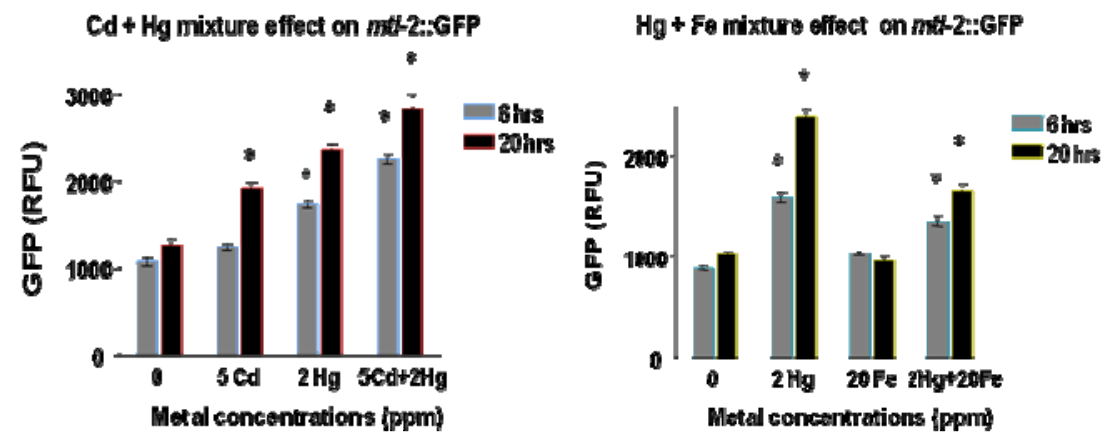

A.

B.

Figure 2: $\quad$ Selected examples of metal-mixture toxicity effects on $m t l-2:: G F P$. Part A: submaximal concentrations of $\mathrm{Cd}^{2+}(5 \mathrm{ppm})$ and $\mathrm{Hg}^{2+}$ (2 ppm) tested both singly and together (plus 0 control), and showing a mildly additive response. Part B: submaximal concentrations of $\mathrm{Hg}^{2+}(2 \mathrm{ppm})$ and $\mathrm{Fe}^{3+}(20 \mathrm{ppm})$ tested both singly and together (plus 0 control), showing $\mathrm{Fe}^{3+}$ inhibition of $\mathrm{Hg}^{2+}$ induction in this mixture. Significant changes $(p<0.01)$ relative to zero controls are indicated by asterisks. 


\section{Discussion}

High-throughput monitoring of GFP reporter transgene expression is obviously much cheaper than using gene array approaches, though only a targeted selection of genes can be covered. This limitation is particularly apparent in the case of large gene families such as the cyp and gst groups. For other stress-responsive pathways, our coverage is around $50 \%$ and could easily be extended further. Gene expression changes outside the SRN are not covered, which may exclude important response genes (e.g. the $c d r$ or aip genes responding to $\mathrm{Cd}$ or As). The use of GFP reporters as transcriptional fusion genes also imposes limitations, since dynamic changes in gene expression will not be reflected in the levels of relatively stable GFP; translational fusions and destabilised GFP variants could be used to circumvent this problem in future. Furthermore, some time (of the order of 1-2 hrs) is required for GFP to be translated, folded and auto-oxidised before any fluorescent signal can be detected; thus a lack of response at $4 \mathrm{hrs}$ need not imply that the gene under investigation still remains to be induced.

Even acknowledging these limitations, Table 2 shows how this approach can provide a more global view of (in this case) patterns of stress-gene response to a series of metals [cf. LC50 data in 15]. Broadly similar gene expression patterns are induced by the 3 group IIB metals $\left(\mathrm{Zn}^{2+}, \mathrm{Cd}^{2+}, \mathrm{Hg}^{2+}\right)$ and by $\mathrm{Cu}^{2+}$, whilst more divergent patterns are apparent for $\mathrm{Fe}^{3+}, \mathrm{Cr}^{6+}$ and the metalloid $\mathrm{As}^{3+}$. As expected, both $m t l$ genes are inducible by divalent metals - mtl-2 more strongly than $m t l-1[4,16]$. Responses to $\mathrm{As}^{3+}$ and to $\mathrm{Fe}^{3+}$ (mtl-2 only) may reflect interference with the handling of divalent metals, as implied also by mathematical modelling and mixture effects shown in Figure 2 (see end of Results). Among the $h s p$ group, the two $h s p-16$ genes show the strongest responses (apart from $\mathrm{Cr}^{6+}$ ), while the $h s p-3$ gene (encoding an ER-specific HSP70) is most strongly induced by $\mathrm{Cd}^{2+}$ and $\mathrm{Cu}^{2+}$. The oxidative stress genes are mostly rather weakly induced, apart from the extracellular superoxide dismutase encoded by the sod-4 gene. Of the two glutathione peroxidase genes tested, C11E4.1 (GPB) expressed in intestine shows a somewhat greater range of metal sensitivity than is the case for T09A12.2 (GPA) expressed in body wall. Perhaps most surprising is the strong induction of all three cyp genes by most of the metals tested (less so by $\mathrm{Cr}^{6+}$ and $\mathrm{Fe}^{3+}$ ), perhaps reflecting metal-induced changes in general metabolism, since metals themselves cannot be metabolised by cytochrome P450-mediated processes such as epoxidation. This feature has also been noted by others, since many cyp genes are prominently up-regulated by $\mathrm{Cd}^{2+}$ in gene array studies [1]. In general, the transcription factor (TF) genes studied (elt-2, $h s f-1, s k n-1, c e p-1$ and $d a f-16)$ show fewer and weaker responses to metal stressors, though cep-1 is strongly induced by $\mathrm{Zn}^{2+}$ and $d a f-16$ by $\mathrm{Fe}^{3+}$. These TFs are expressed widely in C. elegans; thus increased expression of their genes may represent a last-ditch attempt to up-regulate appropriate target genes. Although many previous studies have compared the responses of single SRN output genes to multiple stressors (e.g. $[4,10-12,14,16])$, this is the first report to make such comparisons for multiple output genes in different stress pathways. 
In summary, this GFP-reporter approach provides a broad overview of stressgene expression patterns that would otherwise need many expensive gene arrays. These quantitative data can be incorporated into mathematical modelling of the SRN and of its component sub-networks, based on the known genetic circuitry of these systems. One advantage of such modelling is that it can generate rational predictions about the likely toxicity of mixtures; thus the mixture data shown in Figure 2 can be accommodated by a mathematical model of the $m t l$ sub-network. Future work will extend this modelling, first to other regulatory sub-networks (e.g. the oxidative stress genes controlled by SKN-1) [5], and then to the entire SRN. Model-based predictions of likely mixture toxicity can be readily tested in the laboratory - and if found to be inaccurate, the model parameters can be adjusted accordingly. Through this iterative process of model refinement, model predictions for simple toxicant mixtures should become increasingly accurate over time. This represents a rational approach to a key problem in environmental toxicology - namely the fact that pollutants rarely come singly, and extrapolating the toxicity of mixtures from that of single constituents has rarely proved simple.

\section{Acknowledgements}

The authors gratefully acknowledge the contributions of David Baillie and Bob Johnsen (Simon Fraser University, Vancouver, Canada) for providing transgenic BC strains, and of UK-IERI (Major Award MA-05) for their financial support.

\section{References}

[1] Cui, Y., McBride, S.J., Boyd, W.A., Alper, S. \& Freedman, J.H., Toxicogenomic analysis of Caenorhabditis elegans reveals novel genes and pathways involved in the resistance to cadmium toxicity, Genome Biology 8, R122, 2007.

[2] de Pomerai, D., Madhamshettiwar, P., Anbalagan, C., Loose, M., Haque, M., King, J., Kar Chowdhuri, D., Sinha, P., Johnsen, R. \& Baillie, D., The stress-response network in animals: development of a predictive mathematical model, Open Toxicology Journal 2, pp. 71-76, 2008.

[3] Murphy, C. McCarroll, S.A., Bargmann, C.I., Fraser, A., Kamath, R.S., Ahringer, J., Li, H. \& Kenyon, C., Genes that act downstream of DAF-1 to influence the lifespan of C. elegans, Nature 424, pp. 277-84, 2003.

[4] Swain, S.C., Keusekotten, K., Baumeister, R. \& Sturzenbaum, S.R., C. elegans metallothioneins: new insights into the phenotypic effects of cadmium toxicosis, Journal of Molecular Biology 341, pp. 951-959, 2004.

[5] An, J.-H., \& Blackwell, T., SKN-1 links C. elegans mesendodermal specification to a conserved oxidative stress response, Genes and Development 17, pp. 1882-1893, 2003.

[6] McElwee, J.J., Schuster, E., Blanc, E., Thomas, J.H. \& Gems, D., Shared transcriptional signature in Caenorhabditis elegans dauer larvae and longlived daf-2 mutants implicates detoxification systems in longevity assurance, Journal of Biological Chemistry 279, pp. 44533-44543, 2004. 
[7] McGhee, J.D., Fukushige, T., Krause, M.W., Minnema, S.E., Goszczynski, B., Gaudet, J., Kohara, Y., Bossinger, O., Zhao, Y., Khattra, J., Hirst, M., Jones, S.J.M., Marra, M.A., Ruzanov, P., Warner, A., Zapf, R., Moerman, D.G. \& Kalb, J.M., ELT-2 is the predominant transcription factor controlling differentiation and function of the C. elegans intestine, from embryo to adult, Developmental Biology 327, pp. 551-565, 2009.

[8] Derry, W.B., Putzke, A. \& Rothman, J., Caenorhabditis elegans p53: role in apoptosis, meiosis, and stress resistance, Science 294, pp 591-595, 2001.

[9] Menzel, R., Bogaert, T. \& Achazi, R., A systematic gene expression screen of Caenorhabditis elegans cytochrome P450 genes reveals CYP35 as strongly xenobiotic inducible, Archives of Biochemistry and Biophysics 395, pp. 158-168, 2001.

[10] Leiers, B., Kampkotter, A., Grevelding, C.G., Link, C.D., Johnson, T.E. \& Henkle-Duhrsen, K., A stress-response glutathione S-transferase confers resistance to oxidative stress in Caenorhabditis elegans, Free Radical Biology and Medicine 34, pp. 1405-1415, 2003.

[11] Hasegawa, K., Miwa, S., Isomura, K., Tsutsumiuchi, K., Taniguchi, H. \& Miwa, J., Acrylamide-responsive genes in the nematode Caenorhabditis elegans, Toxicological Sciences 101, pp. 215-225, 2008.

[12] David, H.E., Dawe, A.S., de Pomerai, D.I., Jones, D., Candido, E.P.M., \& Daniells, C., Construction and evaluation of a transgenic hsp16-GFP-lacZ Caenorhabditis elegans strain for environmental monitoring, Environmental Toxicology and Chemistry 22, pp. 111-118, 2003.

[13] Hunt-Newbury, R., Viveiros, R., Johnsenn, R., Mah, A., Anastis, D., Fang, L., Halfnight, E., Lee, D., Lin, J., Lorch, A., McKay, S., Okada, H.M., Pan, J., Schultz, A.K., Tu, D., Wong, K., Zhao, Z., Alexeyenko, A., Burglin, T., Sonnhammer, E., Schnabel, R., Jones, S.J., Marra, M.A., Baillie, D.L. \& Moerman, D.G., High throughput in vivo analysis of gene expression in $C$. elegans, PLoS Biology 5, e237, 2007.

[14] Dennis, J.L., Mutwakil, M.H.A.Z., Lowe, K.C. \& de Pomerai, D.I., Effects of metal ions in combination with a non-ionic detergent on stress responses in a transgenic nematode, Aquatic Toxicology 40, pp. 37-50, 1999.

[15] Williams, P.L. \& Dusenbery, D.B., Aquatic toxicity testing using the nematode Caenorhabditis elegans, Environmental Toxicology and Chemistry 9, pp. 1285-1290, 1990.

[16] Moilanen, L.H., Fukushige, T. \& Freedman, J.H., Regulation of metallothionein gene transcription: identification of upstream regulatory elements and transcription factors responsible for cell-specific expression of the metallothionein genes from Caenorhabditis elegans, Journal of Biological Chemistry 274, pp. 29655-29665, 1999. 